\title{
A divisão sexual do trabalho na mineração no quadrilátero ferrífero de Minas Gerais: apontamentos e questões introdutórias que (des)inviabilizam (novas) sujeitas que são exploradas na mineração*
}

The sexual division of mining work in quadrilater Mine ferrifero: notes and introductory questions that (dis) make (new) subjects that are exploited in mining

La división sexual del trabajo minero en el cuadrilato de Minas ferriferio: notas y preguntas introductorias que (dis)hacen (nuevos) temas que se exploran en minería

Bianca Lemos Coelho

Universidade Federal de Ouro Preto

Kyara Mariana Corgosinho Silva

Universidade Federal de Ouro Preto

RAINER BOMFIM

PUC-MG

RESUMO As transformações no trabalho da mulher são contínuas, mas a crescente ocupação feminina no mercado laboral não foi suficiente para acabar com a desigualdade de gênero. A divisão sexual do trabalho continuou a mostrar as desigualdades sistemáticas que permaneceram em situações diferentes, mediante "novas faces" da discriminação do trabalho feminino. Sob esse aspecto, a desigual ocupação feminina na atividade de mineração é profunda e evidencia os abismos entre os gêneros no mercado de trabalho. Nesse sentido, na mineração, é possível observar as limitações que enfrentam as mulheres, vez que esses espaços foram historicamente ocupados pela figura masculina. Nos termos da divisão sexual do trabalho, a atividade de mineração exige força física e trabalhos pesados, realizados em ambientes inóspitos e insalubres que, via de regra, são associados ao estereótipo masculino, visto que exigem força e persistência; já as mulheres, principalmente as brancas, são

* O trabalho mostra-se uma discussão recente da forma como são conduzidas as questões relacionadas à mineração. Sem ter o objetivo de esgotar a discussão se propõe a construção desse trabalho para nortear e abrir espaços para novas pesquisas. A construção desse texto não seria possível sem a orientação da pesquisadora Dra. Flávia Souza Máximo Pereira que é um norte de pesquisa para todo o trabalho. 
associadas aos trabalhos mais leves, fáceis, limpos e delicados. Minas Gerais é uma área de histórica exploração de minério desde a colonização, de modo que é possível acompanhar o desenvolvimento social e econômico promovido por essa atividade. Tendo como cenário esse segmento industrial, a presente pesquisa jurídico-sociológica buscou verificar em qual medida a divisão sexual do trabalho permanece na atividade de mineração em Minas Gerais, verificando a inserção, permanência e ascensão profissional das mulheres nessa área. Palavras-chaves: Direito do trabalho; Divisão sexual do trabalho; Mineração.

Abstract Changes in women's work are continuous, but the growing female occupation in the labor market has not been sufficient to end gender inequality. The sexual division of labor continued to show the systematic inequalities that remained in different situations through "new faces" of female labor discrimination. In this regard, the unequal female occupation in mining activity is profound and highlights the gaps in the labor market. In this sense, in mining, it is possible to observe the limitations facing women, since these spaces were historically occupied by the male figure. In terms of the sexual division of labor, mining requires physical strength and heavy work in harsh and unhealthy environments, which are usually associated with the male stereotype, as they require strength and persistence; whereas women are associated with lighter, easier, clean and delicate work. Minas Gerais is a historical area of exploration of mining since the colonization to the present times is possible to follow the social and economic development promoted by this activity. Against the background of this industrial segment, this legal-sociological research sought to verify to what extent the sexual division of labor remains is the mining activity in Minas Gerais verifying the insertion, permanence and professional rise of women in this area.

Keywords: Labor Law; Sexual Division of Labor; Mining.

RESUMEN Los cambios en el trabajo de las mujeres son continuos, pero la creciente ocupación femenina en el mercado laboral no ha sido suficiente para terminar con la desigualdad de género. La división sexual del trabajo continuó mostrando las desigualdades sistemáticas que se mantuvieron en diferentes situaciones a través de "caras nuevas" de la discriminación laboral femenina. A este respecto, la desigual ocupación femenina en la actividad minera es profunda y pone de relieve las brechas de género en el mercado laboral. En este sentido, en la minería, es posible observar las limitaciones que enfrentan las mujeres, ya que estos espacios fueron ocupados históricamente por la figura masculina. En términos de la división sexual del trabajo, la minería requiere fuerza física y trabajo pesado en entornos hostiles y poco saludables, que generalmente están asociados con el estereotipo masculino, ya que requieren fuerza y persistencia; Las mujeres, especialmente las mujeres blancas, están asociadas con un trabajo más ligero, más fácil, limpio y delicado. Minas Gerais es un área de exploración histórica de minerales desde la colonización, por lo que es posible seguir el desarrollo social y económico promovido por esta actividad. En el contexto de este segmento industrial, esta investigación jurídico-sociológica buscó verificar hasta qué punto la división sexual del trabajo permanece en la actividad minera en Minas Gerais, verificando la inserción, la permanencia y el avance profesional de las mujeres en esta área.

Palabras clave: Derecho laboral. División sexual del trabajo. Minería. 


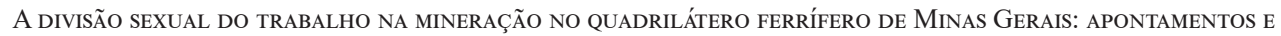
QUESTÕES INTRODUTÓRIAS QUE (DES)INVIABILIZAM (NOVAS) SUJEITAS QUE SÃO EXPLORADAS NA MINERAÇÃO

\section{INTRODUÇÃO}

Sob a vertente metodológica jurídico-sociológico (GUSTIN; DIAS, 2012 p. 22) serão apresentados conceitos introdutórios da divisão internacional do trabalho dentro da mineração, para depois adentrar no contexto do quadrilátero ferrífero, tendo como marco teórico o conceito de divisão sexual do trabalho elaborado por Helena Hirata e Danièle Kergoat (2007). As sistemáticas desigualdades de trabalho entre homens e mulheres fizeram parte da pauta de protestos feministas desde a década de setenta e, a partir deles, incorporou-se no âmbito da academia a divisão sexual do trabalho ${ }^{1}$.

Aborda-se a construção histórica e social dos gêneros no trabalho, os quais têm como características a designação prioritária dos homens à esfera produtiva ${ }^{2}$ e das mulheres à esfera reprodutiva ${ }^{3,4} \mathrm{e}$, simultaneamente, a apropriação pelos homens das funções com maior valor social adicionado (HIRATA; KERGOAT, 2007, p. 599).

Dessa forma, na construção da história moderna, as mulheres sofreram com as desigualdades no trabalho, seja pelo acúmulo do trabalho doméstico e de cuidado - não reconhecido em termos jurídicos, econômicos e sociais - seja pela discriminação de gênero no trabalho produtivo. A divisão sexual do trabalho é estruturada mediante o princípio da hierarquia entre o trabalho masculino e feminino, em que o trabalho de um homem sempre vale mais do que o de uma mulher, assim como por meio do princípio da separação que determina que existem "trabalhos para homens" e "trabalhos de mulher" (HIRATA; KERGOAT, 2007, p. 599).

Os princípios que fundamentam a divisão sexual do trabalho são baseados em estereótipos biológicos de gênero ou em argumentos moralistas que se refletem na própria norma do Direito do Trabalho.

Assim, tendo em vista as relações sociais de sexo, a presente pesquisa jurídico-teórica visa investigar em qual medida e por que a divisão sexual do trabalho permanece na atividade de mineração em Minas Gerais na contemporaneidade, verificando a inserção, permanência e ascensão profissional das mulheres nessa área.

Como recorte, tem-se que a mineração é uma atividade recorrente no Brasil desde a colonização e a região do Quadrilátero Ferrífero ${ }^{5}$ em Minas Gerais é famosa por suas

1 São duas as acepções deste conceito trazidas por Helena Hirata e Danièle Kergoat (2007, p. 599): a primeira estuda a distribuição diferencial entre homens e mulheres, ofícios e profissões, variações dessa distribuição no tempo e no espaço, analisando a sua associação à divisão desigual do trabalho doméstico entre os sexos. A segunda acepção afirma que a divisão sexual do trabalho articula a descrição real como reflexão sobre os processos mediante os quais a sociedade utiliza essas diferenças para hierarquizar as atividades e, portanto, os sexos, para criar um sistema de gênero.

2 Em termos marxistas, é aquele que insere um bem ou serviço no mercado, capaz de gerar mais-valia, ou seja, autovalorização do valor decorrente do tempo de trabalho excedente à disposição do capitalista.

3 Em termos marxistas, é aquele que não gera mais-valia direta, pois é desenvolvido no âmbito lar, sem inserir nenhum bem ou serviço no mercado, imbricado na falaciosa esfera de afeto feminino.

4 Ressalta-se que este é um dispositivo de gênero destinado às mulheres brancas burguesas, na medida em que cuidar dos seus próprios filhos e ter um relacionamento estável é ainda um privilégio para mulheres negras periféricas. Além disso, tais mulheres sempre exerceram o trabalho produtivo em condições precárias e desumanas.

5 O que se entende como Quadrilátero Ferrífero engloba os municípios de: Bom Jesus do Amparo, São Gonçalo do Rio Abaixo, Barão de Cocais, Santa Bárbara, Catas Altas, Alvinópolis, Mariana, Ouro Preto, Ouro Branco, Congonhas, Jeceaba, Belo Vale, Moeda, Itabirito, Rio Acima, Brumadinho, Mario Campos, Sarzedo, Ibirité, Nova Lima, Raposos, Sabará, Caeté, Belo Horizonte, Santa Luzia no Estado de Minas Gerais (GEOPARK QUADRILÁTERO FERRÍFERO, 2019). 
riquezas em minérios. Mais de quatro séculos após o início da exploração minerária nessa região, o Quadrilátero Ferrífero ainda é a região de maior extração de ferro no país, mas a atividade ainda é predominantemente exercida por homens. Ao longo dos anos, mesmo que alcançadas algumas mudanças sociais e jurídicas para as mulheres, é notável a distância entre os sexos, ou seja: mudam-se as maneiras como ocorrem a submissão da mulher, mas a submissão permanece.

Os desafios para a inserção, permanência e ascensão profissional das mulheres em áreas e funções historicamente masculinas faz com que muitas delas sofram processos binários estereotipados de "masculinização", para que possam ser aceitas e reconhecidas na indústria minerária como competentes e aptas, fato que desrespeita a individualidade da subjetividade feminina.

O artigo está estruturado para abordar o conceito de divisão sexual do trabalho e sua permanência ao longo dos anos, tendo como princípios fundamentais os da separação e hierarquia que submetem o gênero à precariedade laboral (HIRATA; KERGOAT, 2007, p. 577). Em seguida, analisar-se-á a evolução histórica das normas laborais no decurso do tempo, que dificultam a já penosa participação da mulher no mercado de trabalho. Para tanto, serão utilizadas as normas extravagantes, Convenções da Organização Internacional do Trabalho (OIT), as disposições da Constituição Federal de 1998 e as normas da CLT (BRASIL, 1943).

Destarte, serão apresentadas as ineficazes medidas propostas por empresas de mineração presentes no estado de Minas Gerais, para a diminuição da desigual ocupação das mulheres na mineração, bem como as medidas adotadas pela ONG International Women in Mining, corroborada por dados, demonstrando a divisão sexual do trabalho, para que, posteriormente, seja possível realizar uma análise jurídica do tema.

\section{A diVISÃo SEXUAL NA MINERAÇÃo}

No século XX, diante de várias reivindicações feministas que romperam com dicotomia do espaço público-privado, surgiram pautas que buscavam reduzir as desigualdades de gênero no trabalho (HIRATA; KERGOAT, 2007, p. 599).

A divisão sexual do trabalho decorre das relações sociais entre os sexos e é fator primordial para a sobrevivência da relação entre homens e mulheres (HIRATA; KERGOAT, 2007, p. 575). Sua característica principal é a designação dos homens na esfera produtiva, enquanto as mulheres são socialmente destinadas à esfera reprodutiva. Assim, essas desigualdades são sistemáticas e ditam a inferiorização das mulheres nas relações de trabalho (HIRATA; KERGOAT, 2007, p. 575).

Ao longo dos anos, com o avanço das indústrias e de novos serviços, algumas mulheres puderam ocupar novos cargos, avançando diante da iminente necessidade da indústria capitalista, e, parte delas pôde estabelecer relações de emprego em áreas masculinizadas. Contudo, tais mudanças não foram suficientes para superar o distanciamento entre os gêneros, que continuou condicionando mulheres à realização de tarefas domésticas e de cuidado, e precarizando o labor feminino no espaço produtivo.

Segundo Toledo (2008, p. 39) foi durante a Revolução Industrial que grandes massas de mulheres deram entrada no mercado de trabalho na Inglaterra, entre 1770 e 1830. 
O período foi de inserção da família na engrenagem de produção e, mais do que isso, transformou a mulher em operária (TOLEDO, 2008, p. 38). Trata-se de um período de introdução da maquinaria ao longo do processo de produção de mercadorias e de grandes deslocamentos de trabalhadores para os centros fabris, vez que a oferta de empregos era grande (TOLEDO, 2008, p. 39).

A explosão da indústria trouxe muitas mudanças para as mulheres, as quais saíram de suas casas para se juntar à classe operária que trabalhava dia e noite na tentativa de alimentar as ambições patronais da época (TOLEDO, 2008, p. 39). Mesmo sendo retirada do seio familiar para alimentar as necessidades da indústria, não foi criada uma alternativa para os trabalhos domésticos que se acumulavam às responsabilidades dessas trabalhadoras, as quais passaram a laborar em turnos extensos e em duplicidade (TOLEDO, 2008, p. 37).

Nesse sentido, ainda que a participação da mulher na indústria tenha sido um passo importante para que ela se libertasse do espaço reprodutivo, foi também a partir de sua participação nos processos de produção que se legitimou a dupla jornada feminina: mulheres continuaram sendo exploradas em casa e, agora, concomitantemente, nas fábricas, submetidas a duas funções sociais, sem que houvesse o devido reconhecimento jurídico, econômico e social.

A precariedade acompanhou essas mulheres desde o início da industrialização capitalista moderna. Marx, em sua obra "O capital", ilustra esta realidade:

[...] a maquinaria, ao tornar inútil a força do músculo, permite empregar trabalhadores sem força muscular ou sem um desenvolvimento físico completo, que possuem, no entanto, uma grande flexibilidade em seus membros. O trabalho da mulher e da criança foi, portanto, o primeiro grito da aplicação capitalista da maquinaria. Desse modo aquele instrumento gigantesco criado para eliminar trabalho e operários se convertia imediatamente em meio de multiplicação do número de assalariados, colocando todos os indivíduos da família operária, sem distinção de idade ou sexo, sob a dependência imediata do capital. (MARX, 1987, v. 1, p. 235).

Para Toledo (2008, p. 45), a transferência dos processos de manufatura para a indústria foi essencial para a incorporação do trabalho feminino na produção social. O maquinário dispensava a força dos músculos, possibilitando que mulheres e crianças exercessem atividades antes delegadas apenas aos homens (TOLEDO, 2008, p. 46).

Entretanto, esse não foi o único motivo para que as mulheres fossem incorporadas nas indústrias, pois havia grande demanda por força de trabalho, no intuito de manter a produtividade contínua, em uma exigência capitalista de maximização dos lucros (TOLEDO, 2008, p. 46). Recorreu-se à força de trabalho feminina não como uma opção valorizada e competente como os homens, mas por não ter mais homens suficientes e disponíveis (TOLEDO, 2008, p. 46).

Nesse sentido, o capitalismo apropriou-se das diversas manifestações sociais do patriarcalismo. Historicamente, a mão de obra feminina e infantil foi mais utilizada nas primeiras indústrias, seja no Brasil ou em âmbito mundial, por se tratarem de força de trabalho mais "dócil"6 e facilmente controlável (BARROS, 2016, p. 254).

6 Destaca-se que este é um dispositivo de gênero utilizado para caracterizar mulheres brancas, pois mulheres negras sempre trabalharam em condições mortificantes no espaço produtivo. 
O início da regulamentação jurídica-trabalhista se traduz em normas de proteção ao trabalho da mulher e da criança que, de certa forma, fizeram com que as fábricas passassem a contratar homens, em razão do alto valor agregado da força de trabalho feminina-infantil, que começou a ter direitos mínimos (BARROS, 2016, p. 254).

Com o posterior surgimento de normas laborais de proteção ao trabalho dos homens, a mulher começou a ser considerada trabalhadora produtiva secundária, pois seu lugar por essência era o lar, e, por isso, quando exercia o trabalho produtivo era mal remunerada (BARROS, 2016, p. 254).

Na década de 70, movimentos feministas na França, começaram a questionar essa dupla jornada feminina que envolvia o trabalho reprodutivo e o trabalho produtivo precário. (HIRATA; KERGOAT, 2007, p. 575). O trabalho contínuo realizado por essas mulheres não era para o seu próprio cuidado, mas sim em nome de um construto social do amor feminino e do dever materno, de modo que as atribuições da esfera doméstica não eram consideradas trabalho, sendo falaciosamente introduzidas na esfera do afeto (HIRATA; KERGOAT, 2007, p. 575).

Diante de tantas discussões à época e em meio a insatisfações das feministas na França, surge o termo "divisão sexual do trabalho", o qual carregava ambições maiores do que apenas denunciar a dura exploração vivida por essas mulheres que tiveram atividades domésticas compulsórias. A intenção era que as formas de trabalho fossem repensadas, de modo que o labor de cuidado e doméstico também fossem reconhecidos jurídica e economicamente, como o trabalho produtivo realizado por homens.

No entanto, mesmo que o trabalho reprodutivo fosse valorizado jurídica e economicamente como o produtivo, as mulheres continuariam a enfrentar desigualdades de gênero decorrentes do princípio da hierarquia e da separação que estruturam a divisão sexual do trabalho.

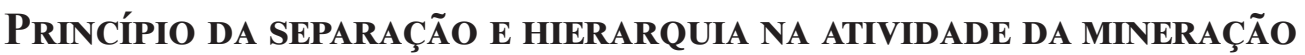

As definições do que seria "trabalho de homem" e "trabalho de mulher" trazem ao centro das discussões da divisão sexual do trabalho um contexto hierárquico das relações entre os gêneros, ditando o que são tarefas destinadas às mulheres e que se diferem daquelas realizadas pelos homens, em um reflexo da sociedade patriarcal.

Embora as formas da divisão sexual do trabalho sejam mutáveis ao longo da história tanto no espaço quanto no tempo, existem dois princípios organizadores das relações entre os sexos: o princípio da separação e o princípio da hierarquia, os quais permanecem em qualquer contexto estudado (HIRATA; KERGOAT, 2007, p. 577).

Os princípios da separação e da hierarquia são facilmente reproduzidos na maioria das sociedades ao longo da história. Helena Hirata (2010, p. 74) demonstra como tais mecanismos são legitimados pela ideologia biológica sexista, a qual inferioriza o gênero à condição de fragilidade física e debilidade mental feminina, limitando as práticas sociais a "papéis sociais" sexuados que definem qual o destino de homens e mulheres.

O princípio da separação preceitua que há trabalhos de homens e de mulheres, sendo a esfera reprodutiva reservada a estas, enquanto que aqueles, prioritariamente, atuam no 
âmbito produtivo (HIRATA; KERGOAT, 2007, p. 579). Os trabalhos das mulheres, ainda quando exercidos fora do lar, são voltados ao cuidado, remetendo à delicadeza, a atividades mais leves, em uma visão estereotipada que representa o prolongamento do labor feminino de caráter reprodutivo.

Já o princípio da hierarquia dita que o trabalho do homem "vale" mais do que o trabalho realizado pela mulher e está intimamente ligado ao princípio da separação (HIRATA; KERGOAT, 2007, p. 577). Ao definir o que é "trabalho de mulher" e "trabalho de homem", há uma atribuição prioritária das funções de maior valor social ao gênero masculino. Os trabalhos masculinos são mais valorizados, sejam em âmbito jurídico, econômico ou social. Mesmo que uma mulher ocupe o mesmo cargo que um homem, e ambos tenham as mesmas qualidades profissionais, seu salário é menor, ou o trabalho exercido por ele gera mais prestígio, ou é mais importante do que o dela, fazendo referência a uma "hierarquia social” (HIRATA; KERGOAT, 2007, p. 577). A interação desses dois princípios gera a divisão sexual do trabalho na mineração, área tipicamente masculina.

A mineração é uma atividade econômica de grande importância histórica para a sociedade brasileira, sobretudo no estado de Minas Gerais. De acordo com o Instituto Brasileiro de Mineração (INSTITUTO BRASILEIRO DE MINERAÇÃO ), Minas é o estado mais importante quando se fala em mineração, extraindo mais de 160 milhões de toneladas/ano de minério de ferro. O estado é responsável por cerca de $53 \%$ de toda a produção brasileira de minerais metálicos e 29\% dos minérios em geral (INSTITUTO BRASILEIRO DE MINERAÇÃO , 2014, p. 2).

Historicamente, essa atividade reproduz graves discriminações de gênero, uma vez que são consideradas, desde o seu surgimento, de destinação masculina, por serem pesadas, sujas, penosas, realizadas, inclusive, em períodos noturnos, em ambientes inóspitos e insalubres. Essas são características que se opõem à concepção cultural patriarcal de trabalho feminino, que deveria ser leve, fácil, limpo e que exige paciência e minúcia (HIRATA, 2010, p. 43).

Para Kergoat, Picot e Lada (2009, p. 160), nessas empresas há um conhecimento prévio do que são ofícios ditos masculinos - nos quais as qualidades são reconhecidas como verdadeiras qualificações e são agregadas ao diploma - e aqueles ofícios ditos femininos - que exigem qualidades inatas, não sendo reconhecidas como qualificações( HIRATA, KERGOAT, 2007). Raquel Quirino explica esta dinâmica que opera também na atividade de mineração:

Desde os pensadores clássicos até as concepções vigentes hoje, a concepção de que a "natureza" das mulheres (emotividade, falta de racionalismo, dependência biológica da maternidade, fragilidade etc.) as tornam inferiores na vida pública. Por isso, a história da mulher é uma história de aprisionamento na esfera doméstica, sendo raros os relatos que a incluem em conceitos e categorias políticas gerais (QUIRINO, 2011, p. 53).

Assim, mesmo com a entrada da mão de obra feminina no espaço produtivo, o gênero não foi desvinculado do trabalho doméstico, isso apenas foi transferido aos seus ofícios, permanecendo a clivagem de tarefas femininas e masculinas em um continuum econômi- 
co-sexual de apropriação feminina no espaço do lar e no mercado de trabalho (HIRATA, 2010, p. 75).

Zuleika Castilhos e Nuria Castro (2006) discorrem sobre as diversas tradições que contribuem para a exclusão e invisibilidade das mulheres na mineração. Em vários países, a presença das mulheres em minas é considerada má-sorte, muitas vezes por superstições e tradições que reproduzem a divisão sexual do trabalho na mineração (CASTILHOS; CASTRO, 2006, p. 89).

No Japão, existem histórias tradicionais que indicam que a presença de uma mulher na mineração causa ciúmes na deusa da montanha, o que pode gerar acidentes nas minas (CASTILHOS; CASTRO, 2006, p. 89). Em países africanos, a presença das mulheres é rejeitada nas áreas de garimpo quando estão menstruadas, sendo consideradas "impuras" e fontes de azar (CASTILHOS; CASTRO, 2006, p. 91). Nos Estados Unidos, mais precisamente na Pensilvânia, se uma mulher fosse encontrada no caminho dos mineradores, eles deveriam retornar às suas casas, já que mulheres representam maldição para a mineração (CASTILHOS; CASTRO, 2006, p. 81).

Essas superstições associadas à ideia de que a mineração é trabalho de homem, justamente pela dificuldade física associada a esse tipo de atividade, consolidam o princípio da hierarquia e da separação.

Isso faz com que as próprias mulheres tenham dificuldade para se enxergarem como profissionais da área, ratificando a invisibilidade feminina na mineração (CASTILHOS; CASTRO, 2006, p. 92). Ainda que os mitos que cercam a atividade minerária que desqualificam as mulheres sejam facilmente desconstruídos, percebe-se que eles estão associados ao machismo que envolve a profissão. São estabelecidos padrões de comportamento masculinos, diretamente atrelados à violência e discriminação, reproduzindo a divisão sexual do trabalho na mineração (CASTILHOS; CASTRO, 2006, p. 101).

Pode-se dizer então que a mineração em Minas Gerais, no Brasil e no mundo é estruturada sob um forte discurso de masculinidade; um discurso conservador que apresenta barreiras à entrada das mulheres, remetendo-se a argumentos contraditórios como o da força física. A discriminação é extravasada na perspectiva dos próprios gestores, a exemplo da percepção do supervisor de uma empresa de mineração que atua em Ouro Preto:

As mulheres têm limitações físicas que muitas vezes não são superadas pela tecnologia. Mas depende muito do seu tipo físico, do interesse, da necessidade. Depende do tipo de criação que ela teve, da necessidade que tem de trabalhar. Mas elas são muito mais organizadas, fazem muito mais coisas ao mesmo tempo. Também trouxeram mais respeito para as áreas. Os homens agora estão mais educados, falam menos palavrões (QUIRINO, 2011, p. 7).

Essa ideia de "hipermasculinidade" submete trabalhadoras a processos estereotipados binários de gênero na atividade de mineração. Nesse sentido, ser lésbica acompanha um estereótipo no imaginário heteronormativo, conectado à masculinidade, levando a uma fácil assimilação hierárquica, como se constata no depoimento de uma trabalhadora de uma empresa de mineração em Minas Gerais: 
No meu caso específico o ambiente é bem agressivo, bem masculino, os caras fazem piadas toscas, dão porrada um no outro, barbáries e vulgaridades, é um canteiro de obra. Então eu acho que o fato de eu ser gay ajudou na minha contratação. De verdade, eu acho. Tanto que esses dias uma pessoa estava comentando que na época do gerente anterior, o coordenador falou 'ó, estou trazendo um reforço para você aí, está vindo uma engenheira boa, você vai gostar. Ela é mais macho do que vocês tudo'[...] (CARRILHO, 2016, p. 113).

Fica nítido que para que uma mulher seja aceita na atividade de mineração, ela deve mimetizar o comportamento masculino na tentativa de que isso a insira em uma posição de visibilidade, ainda que hierarquizada. Sendo a mineração um locus laboral masculino, as mulheres passam a ser tratadas/respeitadas quando incorporam essa masculinidade estereotipada, sufocando e submetendo suas próprias atitudes em nome de uma tolerância discriminatória profissional.

Em 2005, o Centro de Tecnologia Mineral (CETEM) organizou o livro "O Ciclo de Conferências: a questão de gênero e trabalho infantil na pequena mineração sul-americana", com o objetivo de ampliar as discussões sobre a presença de mulheres e crianças nos garimpos e nas pequenas minerações. Apesar da presença maciça do gênero feminino nessas minas, as pesquisas que contabilizam e informam as condições em que essas mulheres trabalham são escassas, refletindo a discriminação sofrida por elas, já que se infere que essas lacunas são resultado da invisibilidade feminina na mineração, uma vez que a maioria das pessoas acredita que esse é um trabalho apenas para homens.

Contudo, dos poucos dados encontrados, cita-se aqueles da pesquisa da Secretaria do Trabalho e Emprego (BRASIL, 2016) que informam que, do total de empregados formais da mineração no Brasil em 2015, apenas 12\% são mulheres, o que reflete a divisão sexual do trabalho em consonância com os princípios da hierarquia e da separação (HIRATA; KERGOAT, 2007). Assim, na contemporaneidade, a mineração é ainda percebida como um locus laboral masculinizado, sob a ótica de inferioridade biológica da mulher e da incorporação de um tipo ideal de trabalhador homem-heterossexual disposto a correr riscos e carregar pesos.

Ademais, muitas mulheres ainda estão inseridas na mineração informal, principalmente aquelas não-brancas, caso em que seu labor subalterno no setor se sobrepõe ao trabalho reprodutivo, sendo considerado como uma extensão de atividades domésticas em auxílio ao marido-provedor, como sugere o índice de 17,8\% de mulheres não remuneradas na mineração brasileira, enquanto entre os homens o mesmo índice é de 3\% (JORGE, 2005, p. 14).

Em um estudo divulgado em outubro de 2017 pela Relação Anual de Informações Sociais (RAIS), foi analisado o número de empregos formais em Minas Gerais no setor de extrativa mineral: nota-se uma queda de 2015 para 2016, em que o número de trabalhadores despenca de 60.108 para 58.165. Em 2016, esse número ainda recua, enquanto os homens sofrem uma redução relativa de $7,89 \%$, as mulheres têm seus empregos reduzidos em $8,57 \%$ na extração mineral.

Evidentemente que a quantidade de mulheres presentes nessas atividades é muito menor do que a quantidade de homens, mas, em momentos de recessão, o gênero feminino ainda tem uma tendência comprovada de estar mais suscetível ao desemprego. 
Portanto, a atividade de mineração é estruturada na discriminação do gênero, porque nega a participação feminina, resultando na invisibilidade completa da mulher nas representações sociais. Se a atividade é de domínio masculino, não há espaço para as mulheres na percepção da sociedade (QUIRINO, 2011, p. 152). É por isso que pouco se conhece no Brasil sobre as condições de trabalho, atividades e inserção econômica feminina na mineração. Apesar de a participação das mulheres fazer parte da nossa história, são quase nulos os registros dessa contribuição, inclusive em Minas Gerais.

Desse modo, é necessário investigar a normativa de trabalho que regulamenta a mineração no Brasil, no intuito de verificar se tais normas, sob um falso intuito protetivo da fragilidade feminina, estão, na verdade, gerando uma discriminação de gênero na atividade.

\section{NORMATIVA DO TRABALHO DA MULHER NA MINERAÇÃo: JURIDIFICAÇÃo DA DIVISÃO SEXUAL DO TRABALHO}

Segundo a Organização Internacional do Trabalho (OIT), estima-se que exista um total de 13 milhões de mineradores espalhados em 55 países (CASTILHOS; CASTRO, 2006, p. 115). O número de pessoas que dependem dessa atividade está entre 80 e 100 milhões (CASTILHOS; CASTRO, 2006, p. 115). Apesar de a mineração ser uma atividade com estereótipo masculino, e omisso quanto à existência feminina, as mulheres estão presentes em 20\% das atividades minerárias da América Latina, $10 \%$ na Ásia e $40 \%$ no continente africano (CASTILHOS; CASTRO, 2006, p. 115).

Em 1948, com o intuito de evitar que o caos ocorrido nas duas guerras mundiais voltasse a esmagar os direitos da população, a Organização das Nações Unidas (ONU) editou a Declaração dos Direitos Humanos.

Os direitos previstos na Declaração são o resultado de lutas sociais e resistências que se deram ao longo da história. Porém, os direitos das mulheres continuaram a ser tratados de forma marginalizada e periférica, caracterizando a invisibilidade feminina diante da hegemonia masculina em instrumentos normativos de direitos humanos. Kimberlé Crenshaw (2002), jurista negra estadunidense, analisa em seu estudo a discriminação do gênero feminino ocultada sob a pretensa universalidade dos direitos humanos, uma vez que o homem-branco-europeu está no centro desses direitos. Apesar da garantia formal, a proteção dos direitos humanos das mulheres ainda era periférica em razão da centralidade da figura masculina:

Consequentemente, apesar da garantia formal, a proteção dos direitos humanos das mulheres ficou comprometida à medida que suas experiências poderiam ser definidas como diferentes das dos homens. Assim, quando mulheres eram detidas, torturadas ou lhes eram negados outros direitos civis e políticos, de forma semelhante como acontecia com os homens, tais abusos eram obviamente percebidos como violações dos direitos humanos. Porém, quando mulheres, sob custódia, eram estupradas, espancadas no âmbito doméstico ou quando alguma tradição lhes negava acesso à tomada de decisões, suas diferenças em relação aos homens tornavam tais abusos periféricos em se tratando de garantias básicas dos direitos humanos. (CRENSHAW, 2002, p. 72). 
Sob essa ótica do homem como sujeito epistêmico dos direitos humanos, em 1935, a Convenção n. 45 da OIT sobre Emprego de Mulheres nos Trabalhos Subterrâneos das Minas foi promulgada. A Convenção proibiu em seu art. $3^{\circ}$ a participação das mulheres em trabalhos subterrâneos nas minas de qualquer categoria, legitimando a divisão sexual do trabalho sob o falso intuito protetivo da fragilidade feminina.

$\mathrm{O}$ art. $3^{\circ}$ da Convenção $n^{\circ} 45$ trouxe exceções apenas para mulheres que ocupam cargo de direção e que não executam trabalho manual, para as trabalhadoras de serviços sanitários e sociais, para as estagiárias em minas subterrâneas, em virtude de seus estudos profissionais) e, para trabalhadora chamada, ocasionalmente, a descer aos subterrâneos da mina, em exercício da profissão de caráter manual (BARROS, 2016, p. 79).

Deve-se ressaltar que os trabalhos realizados nas minerações em subsolo são prejudiciais para qualquer ser humano, seja ele homem ou mulher, de modo que não existe motivo para a proteção única e exclusiva para a mulher, mas o ideal seria a criação de melhores condições laborais para todos e todas (LOPES, 2006, p. 419).

Nesse sentido, o fundamento dessa norma seria a "debilidade física" da mulher, o que reflete o contexto social machista de criação do Direito. A proibição do trabalho da mulher na mineração subterrânea legitima juridicamente falsos argumentos biologizantes de inferioridade feminina, servindo para restringir a mulher de determinados setores laborais.

Cientificamente, não existe um critério biológico que mulheres não podem trabalhar em mineração subterrânea, de modo que a norma laboral apenas juridifica a divisão sexual do trabalho, sem se basear em estudos técnicos (VIEIRA, 2014, p. 104). Portanto, tal norma é de cunho patriarcal, ao considerar a fragilidade da mulher como uma regra absoluta e, assim, estabelecer diferenças de força, afirmando que a capacidade física do homem é, por sua natureza, superior à feminina (VIEIRA, 2014, p. 104).

Essa Convenção ${ }^{\circ} 45$ da OIT foi ratificada pelo Brasil em 1938, mas entende-se que a norma não foi recepcionada pela Constituição de 1988 (CF/88), a qual garantiu a igualdade de trabalho entre homens e mulheres (VIEIRA, 2014, p. 104).

Talvez a mais importante Convenção da OIT para o alcance da igualdade seja a n. 100, ratificada em 1951 pelo Brasil, a qual tratou da igualdade salarial entre homens e mulheres e das formas de discriminação do gênero feminino, representando uma mudança de paradigma. Revista e ampliada pelo Brasil em 1979, foi recepcionada por meio do Decreto n. 89.468 de 1984, como norma de caráter protetivo (BRASIL, 1984).

Sete anos após a Convenção n. 100, foi proclamada a Convenção n. 111, ratificada pelo Brasil em 1965, a qual no seu art. $1^{\circ}$ estabeleceu que as mulheres não podem ser discriminadas em suas profissões e trabalho.

Qualquer distinção, exclusão ou preferência fundada em raça, cor, sexo, religião, opinião, política, ascendência nacional, origem social, ou outra distinção, exclusão ou preferência especificada pelo Estado Membro interessado, qualquer que seja sua origem jurídica ou prática e que tenha por fim anular ou alterar a igualdade de oportunidades ou de tratamento no emprego ou profissão (ORGANIZAÇÃO INTERNACIONAL DO TRABALHO, 1958). 
Posteriormente, a Constituição de 1988, em seu art. 5º estabeleceu a igualdade entre homens e mulheres, em direitos e deveres, configurando-se como um marco histórico legal na luta contra as discriminações vividas pelas mulheres. No mesmo sentido, tem-se o art. $3^{\circ}$, IV, o qual veda a discriminação em razão do sexo. Ademais, a CF/88 proíbe a diferença de salários e a admissão que se baseie em sexo, idade, cor ou estado civil, com previsão no art. $7^{\circ}$, XXX (BRASIL, 1988).

A Constituição Federal de 1988 também positivou no art. 226, parágrafo 5º que direitos e deveres conjugais devem ser exercidos de forma igual por homens e mulheres, na tentativa de acabar com o patriarcado brasileiro. Porém, o direito formal ainda se distancia da realidade sociológica-cultural patriarcal vivenciada por mulheres, inclusive na mineração, como já foi demonstrado.

Soma-se à invisibilidade feminina na mineração a presença tímida dessas mulheres nos sindicatos. As negociações coletivas são lideradas majoritariamente por homens, e são nelas que se deliberam condições de acesso, remuneração e exercício do trabalho.

Na Convenção Coletiva de Trabalho da Federação dos Trabalhadores nas Indústrias Extrativas do Estado de Minas Gerais (FTIEMG, 2017), apenas uma das quarenta cláusulas trata de temática exclusiva do labor feminino. A cláusula reproduz a lógica da maternidade inerente à mulher, o que pode gerar discriminação de gênero, também presente na Consolidação das Leis do Trabalho (CLT):

Convenção Coletiva de Trabalho que entre si fazem, de um lado, o SINDICATO DAS INDÚSTRIAS EXTRATIVAS DE OURO, METAIS PRECIOSOS, DIAMANTE E PEDRAS PRECIOSAS, AREIAS, PEDRAS ORNAMENTAIS, LENHA, MADEIRAS, MINERAIS METÁLICOS E NÃO METÁLICOS NO ESTADO DE MINAS GERAIS e, de outro lado, o SINDICATO DOS TRABALHADORES NAS INDÚSTRIAS DE EXTRAÇÃO VEGETAL, CARVOEJAMENTO, REFLORESTAMENTO E SIMILARES DO ESTADO DE MINAS GERAIS mediante as seguintes cláusulas e condições: DÉCIMA - GESTANTES - GARANTIA DE EMPREGO OU SALÁRIO - As empresas dão garantia de emprego ou salário à empregada gestante, desde a confirmação da gravidez até cinco meses após o parto. (SINDEX, 2017, p. 3).

A proteção à mulher grávida, em termos de garantia no emprego, deveria ser adotada a qualquer trabalhador, sendo vedada a dispensa sem fundamento jurídico e justo motivo, observando-se aquilo que a Constituição de 1988 já prevê em seu art. $7^{\circ}$, I:

São direitos dos trabalhadores urbanos e rurais, além de outros que visem à melhoria de sua condição social: I - relação de emprego protegida contra despedida arbitrária ou sem justa causa, nos termos de lei complementar, que preverá indenização compensatória, dentre outros direitos (BRASIL, 1988).

Portanto, a divisão sexual do trabalho também se reitera nas negociações coletivas, uma vez ausente o sexo feminino em lideranças sindicais, reproduz-se a clivagem masculina quanto às necessidades femininas no mercado de trabalho. A voz feminina é forjada pelo mesmo patriarcado que a enxerga apenas na reprodução, deixando de discutir temas que também têm pertinência como a igualdade salarial, e abordando temas voltados apenas à gestação. 
Diante desse cenário de patriarcado intrínseco às normas do trabalho feminino na mineração no Brasil, esta pesquisa teórica visa estudar algumas medidas elaboradas por empresas e Organizações Não-Governamentais (ONGS) no combate à discriminação de gênero nessa atividade.

\section{CONSTRUÇões DENTRO do CAPITAL: MEdidas PARA A DIMINUIÇÃo dos EFEITOS DA DIVISÃO SEXUAL DO TRABALHO EFETUADAS POR EMPRESAS E OR- GANIZAÇÕES NÃO GOVERNAMENTAIS}

A ONG International Women in Mining - Mulheres na Mineração é uma organização britânica que nasceu em 2006 com o objetivo de auxiliar no desenvolvimento profissional DAS MULHERES NO SETOR MINERAL (INTERNATIONAL WOMEN IN MINING, 2017). É A REDE que mais cresce para mulheres no setor de mineração (INTERNATIONAL WOMEN IN MINING, 2017). A ONG está presente em mais de cem países, dando suporte a mais de cinquenta grupos de mulheres (INTERNATIONAL WOMEN IN MINING, 2017).

Entre os projetos desenvolvidos pela $\mathrm{ONG}$ estão aqueles que auxiliam as mulheres a progredirem em suas carreiras em um programa global de orientação, com a promoção de ações inclusivas que criam impactos e melhoram a representação feminina, assim como a produção de pesquisas e relatórios sobre a contribuição das mulheres na mineração (INTERNATIONAL WOMEN IN MINING, 2017). Em 2013, a Organização lançou um ranking que listava as 100 mulheres mais inspiradoras na promoção da equidade de gênero na mineração ao redor do mundo (INTERNATIONAL WOMEN IN MINING, 2017).

Em relação à atuação das empresas, o Instituto Brasileiro de Mineração (IBRAM), em sua cartilha "Informações sobre a Economia Mineral do Estado de Minas Gerais" (2014, p. 13), apresentou algumas das principais produtoras de bens minerais em Minas Gerais. Entre elas estão: Vale, AngloGold Ashanti, Alcoa.

Com a análise de relatórios anuais de sustentabilidade que demonstram a participação de empregados por gênero e projetos que reduzem a divisão sexual do trabalho na mineração, foi possível acompanhar alguns dados disponibilizados por três empresas atuantes na atividade da mineração em alguns períodos. Os dados estão circunscritos no cenário nacional e demonstram as discrepâncias entre os gêneros na mineração.

A Alcoa, empresa que atua em toda a cadeia produtiva de alumínio em três diferentes estados do país, sendo um deles Minas Gerais, desenvolveu uma rede global intitulada AWN (Alcoa Women's Network), a qual trabalha para a promoção da inclusão e diversidade, com a finalidade de promover a participação de mulheres e melhorar a diversidade de gênero na empresa. Entre as atividades desenvolvidas pela empresa estão cursos de capacitação (INSTITUTO BRASILEIRO DE MINERAÇÃO , 2014, p. 15).

Em seu relatório de sustentabilidade, a empresa apresentou dados que remontam ao aumento da participação de mulheres (INSTITUTO BRASILEIRO DE MINERAÇÃO , 2014, p. 15). Em 2015, elas eram 31\% dos empregados; em 2016, 30\%; e em 2017, 33\% do total de trabalhadores (INSTITUTO BRASILEIRO DE MINERAÇÃO , 2014, p. 15). Já em postos de trabalho superiores, as mulheres são ainda menos presentes. Em 2015, 
eram 23\%; 2016, 30\%; e em 2017 representavam 27\% dos postos superiores (INSTITUTO BRASILEIRO DE MINERAÇÃO, 2014, p. 15).

Outra empresa que incluiu dados sobre a participação feminina em suas atividades é a Anglogold Ashanti, uma das mais antigas mineradoras do país e presente também no estado de Minas Gerais. A mineradora apresentou dados em seu relatório anual de desenvolvimento sustentável: em 2016, o relatório apontava que a empresa contava com 377 mulheres e 4.065 homens, sendo elas 8,5\% do seu pessoal e eles 91,5\% (INSTITUTO BRASILEIRO DE MINERAÇÃO , 2014, p. 17). Uma diferença discrepante de representação do gênero feminino.

Em 2017, a mineradora divulgou que a porcentagem de homens e mulheres na empresa continuou a mesma (INSTITUTO BRASILEIRO DE MINERAÇÃO , 2014, p. 17). Contudo, o dado que mais surpreende foi disponibilizado em 2019, no relatório anual de sustentabilidade, referente a 2018, em que a empresa mostra que o perfil da força de trabalho reduziu a participação das mulheres de $8,5 \%$ para $8 \%$ (INSTITUTO BRASILEIRO DE MINERAÇÃO , 2014, p. 17). Desse modo, a presença das mulheres é mínima na empresa. Apesar do mapeamento de dados da presença feminina ser importante, tal medida não vem representando um aumento real nas oportunidades de empregos formais para mulheres na empresa.

Por sua vez, a Vale, desde 2011, conta com o projeto "Equidade de Gênero", o qual visa aumentar o quadro de mulheres na empresa e na mineração, promovendo ações de conscientização e treinamento de seus empregados (INSTITUTO BRASILEIRO DE MINERAÇÃO , 2014, p. 19). O projeto também promove monitoria para que empregadas menos experientes se desenvolvam (INSTITUTO BRASILEIRO DE MINERAÇÃO , 2014, p. 19).

No Relatório de Sustentabilidade de 2018 da Vale, a empresa apresentou alguns de seus projetos que contribuem para a redução da divisão sexual do trabalho na mineração:

\footnotetext{
Um dos exemplos é o projeto “Talento Não Tem Gênero", responsável por aumentar a participação feminina em unidades operacionais de Minas Gerais e do Pará, com a ocupação de cargos de operação de equipamentos de grande porte. Também foram capacitados $45 \%$ dos líderes do Corredor Sudeste no tema (cerca de 400 pessoas), assim como realizado um programa de Trainee Global, resultando na contratação de um quadro de empregados que contempla $48 \%$ de mulheres, sendo que deste percentual, 57\% delas foram alocadas em áreas operacionais (INSTITUTO BRASILEIRO DE MINERAÇÃO, 2014, p. 19).
}

A empresa alegou que faz avaliações dos princípios de empoderamento feminino para monitorar a participação das mulheres (INSTITUTO BRASILEIRO DE MINERAÇÃO , 2014, p. 19). Outro programa que a Vale participa é o do governo brasileiro Empresa Cidadã: "Alinhada às melhores práticas do mercado, nossa empresa aderiu ao programa do governo brasileiro Empresa Cidadã, que prorroga em 60 dias a licença maternidade (de 120 para 180 dias) e em 15 dias a licença-paternidade (de 5 para 20 dias)." (INSTITUTO BRASILEIRO DE MINERAÇÃO, 2014, p. 19).

Ressalta-se, contudo, que o aumento da licença-maternidade e a disparidade temporal em relação à licença-paternidade é outro exemplo de patriarcado imbricado na normativa laboral brasileira, na medida em que legitima o dever de cuidado do filho à mulher. Nesse 
sentido, Rosele Taveira comenta acerca do falso intuito protetivo do aumento da licença-maternidade que legitima juridicamente a divisão sexual do trabalho:

\begin{abstract}
No caso da licença maternidade, a proteção específica ao gênero não legitima a cultura de que só a mulher tem obrigação de cuidar de seus filhos, ainda que nos primeiros meses de vida? Não se poderia compartilhá-la entre homens e mulheres, como já adotado em muitos países da Europa, observando-se as individualidades e problemáticas de cada família, esta considerada em sua acepção ampla? (TAVEIRA, 2017, p. 144).
\end{abstract}

A cartilha da Vale ainda menciona que, em 2018, o conselho administrativo da empresa era composto em sua totalidade por 12 membros, dos quais 3 eram mulheres. Em 30 de abril de 2019, de acordo com a mesma cartilha, a porcentagem de mulheres foi reduzida, uma vez que o conselho administrativo da empresa passou a contar com 13 membros, mas ainda apenas com três mulheres, ou seja, a ampliação do conselho não refletiu em um aumento das mulheres ocupando cargos de poder (INSTITUTO BRASILEIRO DE MINERAÇÃO , 2014, p. 19).

Isso mostra que a inserção feminina realizada pela empresa é essencialmente decorativa, visto que mantém os seus postos extremamente masculinizados e as poucas mulheres em postos subalternos. Nesse sentido, tratam-se de medidas construídas dentro do capital, pois o feminismo também é capturado por tais empresas de forma seletiva. Em razão da pressão de movimentos feministas nas instituições, públicas ou privadas, há a manipulação de ideais feministas sem uma verdadeira mudança de mentalidade patriarcal nas relações de trabalho, o que é denominado de diversity washing ${ }^{7}$ no mundo corporativo.

Conforme pesquisa da ONU de $2017,45 \%$ das mulheres relatam que a liderança de sua empresa discursa sobre o avanço e participação das mulheres, mas apenas $25 \%$ dizem que a empresa forneceu o apoio real para efetivar tal diversidade de gênero (ONU, 2017).

Portanto, é evidente que há uma dissonância entre o discurso de inserção de mulheres em empresas e a efetivação da diversidade no ambiente de trabalho, o que acaba sendo utilizado como um rótulo para a cooptação capitalista de reivindicações feministas para aumentar suas vendas, sem diminuição da desigualdade de gênero, em uma espécie de representatividade decorativa. E mesmo quando há a inserção de mulheres nas organizações, o seu trabalho fica restrito a questões periféricas concebidas como "femininas", reforçando papéis de gênero.

\title{
CONSIDERAÇões FINAIS
}

A mineração é um marco na história de Minas Gerais desde a invasão europeia. Conforme foi demonstrado, a atividade ainda é considerada um locus de trabalho masculino, o que oculta a participação e contribuição feminina ao longo da história para essa atividade.

7 Derivado do termo greenwashing, que representa uma empresa que divulga a utilização de práticas ecologicamente corretas ou sustentáveis, mas não faz nenhuma mudança significativa além de colocar latas de coleta seletiva em seus espaços. Em termos de equidade de gênero, a mentalidade discriminatória permanece, apesar dos discursos de diversidade. 
O conceito da divisão sexual do trabalho foi abordado como uma construção histórica e social dos gêneros no trabalho que têm como características a designação prioritária dos homens à esfera produtiva e das mulheres à esfera reprodutiva.

A divisão sexual do trabalho na mineração mostra como a opressão feminina nas relações laborais é acentuada pela visão patriarcal, sendo estruturada por dois princípios: o da hierarquia, o que supervaloriza o trabalho do homem e rebaixa o valor do trabalho realizado pelas mulheres; e o princípio da separação, o que delineia o que seria o trabalho de homem e de mulher.

Entre as muitas dificuldades encontradas pelas mulheres, está a falta de reconhecimento jurídico, social e econômico da sua existência na atividade da mineração, bem como da acumulação desse trabalho produtivo precário com as atividades reprodutivas do lar, o que colabora para a perpetuação das desigualdades na área.

Assim, permanecem os estereótipos masculinos e a ausência de legislações trabalhistas eficazes, já que a maioria das normas que regulamentam a mineração são ainda baseadas na inferioridade biológica da mulher e na incorporação de um tipo ideal de trabalhador homem-heterossexual disposto a correr riscos e carregar pesos.

A ausência de lideranças sindicais femininas na mineração é outro fator que não permite que essa atividade reconheça a existência e a importância das mulheres, o que faz com que sejam produzidas normas coletivas que legitimam a divisão sexual do trabalho na área, tornando as mulheres mais uma vez invisíveis.

É necessário que as normas dialoguem com a realidade da divisão sexual do trabalho e não permaneçam apenas no direito formal, incorporando homens e mulheres nas discussões acerca do machismo presente na mineração, assim como na produção normativa laboral.

\section{REFERÊNCIAS}

BARROS, Alice Monteiro. Curso de Direito do Trabalho. São Paulo: LTR, 2016.

BRASIL. Constituição da República Federativa do Brasil de 1988. Nós, representantes do povo brasileiro, reunidos em Assembleia Nacional Constituinte para instituir um Estado Democrático, destinado a assegurar o exercício dos direitos sociais [...]. Diário Oficial da União: seção 1, Brasília, ano 126, n. 191-A, 5 out. 1988. Disponível em: <http://www. planalto.gov.br/ccivil_03/Constituicao/DOUconstituicao88.pdf>. Acesso em: 17 set. 2019.

BRASIL. Decreto-Lei n ${ }^{\circ} 5.452$, de $1^{\circ}$ de maio de 1943. Aprova a Consolidação das Leis do Trabalho. Diário Oficial da União: seção 1, Rio de Janeiro, p. 11937, 9 ago. 1943.

BRASIL. Ministério do Trabalho. Programa de disseminação das Estatísticas do Trabalho. RAIS 2019. [S.l.], 2019. Disponível em: <http://pdet.mte.gov.br/rais?view=default $>$. Acesso em: 14 jul. 2019.

CARRILHO, Anabelle. Mulheres invisíveis, mas necessárias: a negação da feminização no trabalho da mineração. 2016. Tese (Doutorado em Política Social) - Universidade de Brasília, Brasília, 2016. 
CASTILHOS, Zuleika; CASTRO, Nuria. Mulheres na mineração: Restitutio quae será tamem. Rio de Janeiro: CETEM/CNPQ, 2006.

CRENSHAW, Kimberlè Williams. Documento para o encontro de especialistas em aspectos da discriminação racial relativos ao gênero. Revista Estudos Feministas, Salvador, n. 1, 2002.

GEOPARK QUADRILATERO FERRÍFERO. Localização. Belo Horizonte, 2019. Disponível em: <https://www.geoparkquadrilatero.org/?pg=geopark\&id=162\&fbclid=IwAR3NYu7Tt5hr6t F9UQ3DoAEIZPRToGHyFporibDFRC4q_uLayOPr315140U>. Acesso em: 10 dez. 2019.

GUSTIN, Miracy Barbosa de Sousa; DIAS, Maria Tereza Fonseca Dias. (Re)Pensando a Pesquisa Jurídica: Teoria e Prática. Belo Horizonte: Del Rey Editora, 2012.

HIRATA, Helena; KERGOAT, Danièle. Novas configurações da divisão sexual do traba1ho. Cadernos de Pesquisa - Fundação Carlos Chagas, São Paulo, v. 37, n. 132, p. 595609, set./dez. 2007.

HIRATA, Helena. Gênero, classe e raça Interseccionalidade e consubstancialidade das relações sociais. Tempo social, [S.1.], v. 26, n. 1, p. 61-73, 2010

INSTITUTO BRASILEIRO DE MINERAÇÃO (INSTITUTO BRASILEIRO DE MINERAÇÃO ). Avanço das mulheres no setor mineral. 2014. Dispinível em: $<\underline{\text { http://por- }}$ taldamineracao.com.br/INSTITUTO BRASILEIRO DE MINERAÇÃO /INSTITUTO BRASILEIRO DE MINERAÇÃO -lanca- pesquisa-sobre-o-avanco-da-participacao-das-mulheres-no-setor-mineral/>. Acesso em: 05 out. 2019.

INTERNATIONAL WOMEN IN MINING (IWiM). Can a mining law unlock the potencial of women? 2017. Disponível em: <http://internationalwim.org/wp- content/uploads/2017/05/ASI-IWiM-2017-Can-a-mining-law-unlock-the-potential-of- women_FINAL_08_pdf>. Acesso em: 05 out. 2019.

JORGE, Angela. Trabalho Infantil e Gênero na Pequena Mineração Sul-americana. Rio de Janeiro: PROSUL, 2005.

LOPES, M. Cristiane. Direito do trabalho da mulher: da proteção à promoção.Cadernos pagu, São Paulo, n. 26, p. 405-430, 2006.

MARX, Karl. O Capital. Tradução de Reginaldo Sant'anna. Rio de Janeiro: Civilização brasileira, 2004

NAÇÕES UNIDAS. Mulheres na liderança trazem melhor desempenho para as empresas. [S.l.], 2019. Disponível em: https://news.un.org/pt/story/2019/05/1673361. Acesso em: 17 jul. 2019. 
ORGANIZAÇÃO INTERNACIONAL DO TRABALHO (OIT). Convenção n. 45 sobre Emprego de Mulheres nos Trabalhos Subterrâneos das Minas , 1935. Disponível em: $<$ https:/www.diap.org.br/images/stories/OIT/convencao045.pdf $>$. Acesso em: 17 jul. 2019.

ORGANIZAÇÃO INTERNACIONAL DO TRABALHO (OIT). Discriminação em matéria de emprego e ocupação, 1960. Disponível em: <http://www.ilo.org/brasilia/convencoes/ WCMS_235325/lang-pt/index.htm>. Acesso em: 10 jun. 2019.

QUIRINO, Raquel. Divisão Sexual do Trabalho e Gênero na Mineração. VIII Congresso Iberoamericano de Ciência, Tecnologia e Gênero. Disponível em: <http://files.dirppg. ct.utfpr.edu.br/ppgte/eventos/cictg/conteudo_cd/E7_Divis\%C3\%A3o_Sexual_do_Trabalho_e_G\%C3\%AAnero_na_Minera\%C3\%A7\%C3\%A3o.pdf>. Acesso em: 26 jul. 2019.

QUIRINO, Raquel. Mineração também é local de mulher!: Desvendando a (nova?) face da divisão sexual do trabalho na mineração de ferro. 2011. Tese (Doutorado em Educação) - Universidade Federal de Minas Gerais, Belo Horizonte, 2018. Disponível em: <file://C:/Users/raque/Downloads/ppgeducacao_raquelquirino_tesedoutorado\%20(1).pdf $>$. Acesso em: 09 jul. 2019

TOLEDO, Cecília. Mulheres: o gênero nos une, a classe nos divide. São Paulo: Sundermann, 2008

TAVEIRA, Roselene Aparecida. A influência do patriarcado nas leis de proteção ao trabalho da mulher. Carta Capital: Justificando, 2017.

VIEIRA, Regina Stela Corrêa. Saúde e Segurança no Trabalho das Mulheres: A perspectiva de gênero para a proteção e promoção do meio ambiente laboral equilibrado. 2014. Dissertação (Metstrado em Direito) - Universidade de São Paulo, São Paulo, 2014.

\section{DADOS DOS AUTORES}

\section{Bianca Lemos Coelho}

Bacharela em Direito pela Universidade Federal de Ouro Preto. Pós-graduada em Direito pela Faculdade Arnaldo. E-mail: bibilemos@gmail.com

\section{Kyara Mariana Corgosinho Silva}

Bacharela em Direito pela Universidade Federal de Ouro Preto. E-mail: ksilva@gmail. com.br

\section{RAINER BOMFIM}

Doutorando em Direito pela PUC/MG. Mestre em Direito pela Universidade Federal de Ouro Preto. Especialista em Direito Previdenciário pela FAVENI. E-mail: rainerbomfim@ outlook.com

Submetido em: 9-4-2021

Aceito em: 23-9-2021 